\title{
PENDIDIKAN MORAL PERSPEKTIF NASIH ULWAN
}

\author{
Johan Istiadie \& Fauti Subhan \\ (Alumni IAIN Sunan Ampel \& Dosen IAIN Sunan Ampel)
}

\begin{abstract}
Abstrak
Tulisan ini berusaha memotret pemikiran pendidikan moral menurut Nasih Ulwan dan relevansinya dalam menjawab problematika manusia modern. Dalam perspektif Nasih Ulwan, pendidikan moral merupakan serangkaian prinsip dasar moral dan keutamaan sikap serta watak (tabiat) yang harus dimiliki dan dijadikan kebiasaan oleh anak sejak masa pemula hingga ia menjadi seorang mukallaf, yakni siap mengarungi lautan kehidupan.

Di era modern, persoalan yang muncul adalah persoalan fisik dan psikis. Persoalan fisik mengarah pada pengkondisian manusia sebagai objek dari segala produk iptek. Sementara itu persoalan psikis mengarah pada pendangkalan nilai-nilai moral-spiritual akibat dari dominasi produk iptek modern yang skuler. Salah satu problem mendasar di negeri ini adalah krisis moral dan kepercayaan. Krisis tersebut berawal dari ketidakjujuran aparatur Negara dalam menjalankan amanahnya sebagai pemegang kebijakan. Perilaku korupsi dan sejenisnya adalah cermin dari sikap suka bohong, suka mencuri, kenakalan dan penyimpangan. Oleh karena itu ajaran moral Nasih Ulwan amat relevan jika diterapkan di negeri ini demi menjawab problem krisis moral dan kepercayaan yang terjadi.
\end{abstract}

Kata Kunci: Pendidikan Moral, Nasih Ulwan, dan Manusia Modern 


\section{A. Pendahuluan}

Pendidikan merupakan komponen penting dalam kehidupan manusia. Tanpa pendidikan kehidupan manusia tidak bisa berkembang secara wajar. Oleh karena pentingnya pendidikan maka pendidikan menjadi tolak ukur dalam kredibilitas manusia dan peradabannya. Semakin tinggi tingkat pendidikan manusia maka semakin tinggi pula tingkat kredibilitasnya, begitu sebaliknya, semakin rendah tingkat pendidikan manusia maka semakin dipertanyakan tingkat kredibilitas kemanusiaannya. ${ }^{1}$

Pendidikan hendaknya berorientasi pada proses penyiapan peserta didik agar memahami konsep-konsep dasar tentang berprilaku, berfikir secara komprehensif dan integral sebagai pijakan dalam menghadapi berbagai problem yang dihadapinya. Pendidikan juga bertujuan agar peserta didik memiliki kompetensi-kompetensi menyangkut ilmu pengetahuan, keterampilan motorik, dan nilai-nilai moral yang luhur serta mencapai manusia yang memiliki kepribadian yang dipenuhi dengan sifat-sifat Ilahiah.

Selama ini Pendidikan moral termasuk di antara jenis pendidikan yang kurang mendapatkan perhatian layak. Sebab pendidikan lebih menekankan kepada ranah kognitif dan psikomotorik (cognitive and psychomotoric domain) sehingga aspek afektif (affective domain) belum dilaksanakan secara proporsional. Padahal ranah afektif menempati posisi penting dan signifikan bagi normalisasi kehidupan.

Dalam kehidupan di tengah-tengah masyarakat terlihat jelas seolah-olah terjadi dua hal yang sangat paradoks. Pada satu sisi terlihat syiar dan gebyar kehidupan beragama, tetapi di sisi lain dengan mudah disaksikan akhlak masyarakat berubah makin jauh dari nilai-nilai Qurani. $^{2}$ Tumbuh suburnya praktik KKN, kenakalan remaja, dekadensi moral, penyalahgunaan narkotika dan obat terlarang, tawuran antar mahasiswa atau siswa atau penduduk, ketidakjujuran dalam mengerjakan ujian (termasuk ujian nasional), dan masih banyak lagi, menjadi bukti lemahnya iman dan rendahnya nilai-nilai yang dimiliki oleh seorang anak

\footnotetext{
${ }^{1}$ Hanik Yuni Alfiyah, Ta'lim dan Liberasi (Surabaya: LPPM Press, 2008), 1.

${ }^{2}$ Said Agil H. M, Aktualisasi Nilai-nilai Qur'ani dalam Ssistem Pendidikan Islam (Ciputat: PT. Ciputat Press, 2005), 36
}

Jurnal Pendidikan Agama Islam Volume 01 Nomor 01 Mei 2013 Hal $46-60$ 
manusia. Hal ini ironis, karena krisis moral sama artinya dengan krisis akal. $^{3}$

Penekanan pendidikan yang lebih pada aspek kognitif dan psikomotorik dengan kurang memerhatikan pelaksanaan aspek afektif pada lembaga pendidikan hanya akan menghasilkan manusia yang pintar secara intelektual dan ketrampilan, tetapi rendah dan bobrok moral atau akhlaknya. Konsekuensinya, out put lembaga pendidikan menjadi orang yang cerdik pandai (ilmuwan) tetapi bermental jahat sehingga mereka menjadi pejabat yang berjiwa KKN, teknokrat yang membuat kerusakan lingkungan hidup, konglomerat yang bermental penjudi, dan sebagainya. ${ }^{4}$ Realitas tersebut menunjukkan urgennya penanaman nilai-nilai moral pada diri anak didik.

Permasalahan di atas memicu penulis untuk menganggap dan meyakini pentingnya pendidikan moral dikedepankan. Dalam kaitan ini, signifikan untuk menampilkan dan mengkaji pemikiran Abdullah Nasih Ulwan tentang persoalan-persoalan seputar pendidikan yang penuh dengan pesan-pesan moral. Abdullah Nasih Ulwan, dalam bukunya Tarbiyatul Awlad fil Islam banyak mengupas tentang konsep pendidikan anak dalam Islam yang berisi tentang pesan-pesan moral.

Abdullah Nasih Ulwan menawarkan upaya pendidikan nilai atau moral ini dengan cara menanamkan dasar-dasar psikis yang mulia berdasarkan keimanan untuk memelihara hak orang lain guna merealisasikan etika sosial dengan pengawasan dan kritik sosial sehingga tumbuh sikap dan perilaku sosial yang menjunjung tinggi nilai-nilai persaudaraan dan kasih sayang agar terwujud masyarakat yang peduli untuk melaksanakan seruan Amar Ma'ruf Nahi Munkar. ${ }^{5}$

${ }^{3}$ Said Agil H. M,, Aktualisasi Nilai-nilai Qur'ani, 33

${ }^{4}$ Said Agil H. M,, Aktualisasi Nilai-nilai Qur'ani, 25

${ }^{5}$ Mustofa Rohman, "Abdullah Nasih Ulwan: Pendidikan Nilai", dalam A. Khudori Soleh, Pemikiran Islam Kontemporer (Yogyakarta: Jendela, 2003), 47. 
Johan Istiadie \& Fauti Subhan

\section{B. Rumusan Masalah}

1. Bagaimanakah pendidikan moral menurut Abdullah Nasih Ulwan?

2. Bagaimanakah relevansi pemikiran pendidikan moral Abdullah Nasih Ulwan dalam menjawab problematika manusia di era modern?

\section{Metode Penelitian}

Penelitian ini merupakan penelitian kepustakaan (library research). Penelitian ini menghimpun data teks. Dalam hal ini penulis mengadakan pengumpulan buku, artikel, data internet maupun jurnal yang memiliki relevansi dengan pokok kajian penulis. Literatur yang dijadikan sumber data dalam penelitian ini adalah sumber primer (Karya Abdullah Nasih Ulwan, Pendidikan Anak dalam Islam Jilid I-II ${ }^{6}{ }^{6}$ Menuju Ketakwaan ); dan sumber sekuder (karya Mustofa Rahman, Abdullah Nasih Ulwan: Pendidikan Nilai, ${ }^{8}$ Zainal Muttaqien, Metode Pendidikan Anak Menurut Nashih Ulwan'); serta sumber pendukung (berbagai referensi yang terkait dengan tema penelitian).

Dalam melakukan pengolahan data yang berkaitan dengan fokus pemikiran Abdullah Nasih Ulwan tentang Pendidikan Moral, penulis menggunakan tahapan-tahapan sebagai berikut: Deskripsi data, Interpretasi data, dan Analisis data. Analisis yang digunakan adalah analisis isi (content analysis).

\section{Hasil Penelitian}

\section{Biografi Nasih Ulwan}

Bagi yang mendalami tentang masalah pendidikan Islam (tarbiyah), hampir pasti mengenal nama besar ulama Abdullah Nasih Ulwan. Dia dilahirkan di Damaskus, Syiria pada tahun 1928 M. Gelar sarjana dan master diperolehnya dari Universitas Al-Azhar, Kairo,

\footnotetext{
6 Abdullah Nasih Ulwan, Pendidikan Anak dalam Islam, Jilid I, Terjemahan Jamaludin Miri, Cet. III (Jakarta: Pustaka Aman, 2007).

${ }^{7}$ www.dakwah.info, diakses 09/06/2009, pukul: 04.15

${ }^{8}$ Mustofa Rohman, "Abdullah Nasih Ulwan: ..., 48.

9 Lihat di http://elmuttaqie.wordpress.com/2008/05/11/metode-pendidikan-anakmenurut-nashih-ulwan 09/06/09 02.30.35

Jurnal Pendidikan Agama Islam

Volume 01 Nomor 01 Mei 2013

Hal $48-60$
} 
Mesir. Gelar doktor di bidang studi Islam dia dapatkan di Universitas Al Sand di Pakistan. Dia dibesarkan di dalam keluarga yang berpegang teguh pada agama dan mementingkan akhlak Islam dalam pergaulan dan muamalat sesama manusia.

Ayah Nasih Ulwan, Syeikh Said Ulwan adalah seorang yang dikenal di kalangan masyarakat sebagai seorang ulama dan tabib yang disegani. Selain dari menyampaikan risalah Islam di seluruh pelosok Madinah Halb, beliau juga menjadi tumpuan untuk mengobati pelbagai penyakit dengan ramuan akar kayu yang dibuat sendiri. Ketika merawat orang yang sakit, lidahnya senantiasa membaca al Quran dan menyebut nama Allah. Syeikh Said Ulwan senantiasa mendoakan semoga anak-anaknya lahir sebagai seorang ulama 'murabbi' yang dapat memandu masyarakat. Allah memperkenankan doa beliau dengan lahirnya Dr. Abdullah Nasih Ulwan sebagai ulama murabbi (pendidik) ruhani dan jasmani yang disegani pada abad ini. ${ }^{10}$

Keluhuran pekerti Nasih Ulwan merupakan benih dari pendidikan Islam yang meresap dalam jiwanya dan hal itu telah membuatnya sangat disanjung oleh ulama dan masyarakat. Rumahnya senantiasa ramai dikunjungi orang. Sahabat karibnya, Dr. Muhammad Walid menyatakan, Dr. Abdullah Nasih Ulwan adalah seorang yang sangat peramah, murah untuk memberi senyuman kepada siapa saja, pertuturannya sangat mudah difahami, percakapannya senantiasa disulami nasihat dan peringatan, dia juga seorang yang tegas dengan prinsip asas Islam. ${ }^{11}$

Nasih Ulwan sangat gemar menulis. Kertas dan pena senantiasa bersamanya di mana dia berada. Walaupun sibuk dengan kuliah, dakwah dan syarahan, dia tetap menyempatkan waktu untuk menulis. Dia telah menghasilkan hampir lima puluh buah kitab yang membahas tentang berbagai judul. Di antara kitab karangannya yang masyhur ialah: Pendidikan anak-anak di dalam Islam (2 jilid), Hukum

10 http://dakwah.info/main/index.php/biografi-tokoh/405-dr-abdullah-nasih-ulwan 11-06-2009. 05:00

$\frac{11}{11}$ http://dakwah.info/main/index.php/biografi-tokoh/405-dr-abdullah-nasih-ulwan $\underline{11-06-2009.05: 00}$ 
zakat menurut empat mazhab, Pemuda Islam dalam menghadapi serangan musuh, Menolak keraguan yang didatangkan musuh. ${ }^{12}$

Setiap tulisan yang dihasilkan oleh Nasih Ulwan bukanlah sekedar tulisan biasa. Ia adalah tulisan yang lahir dari hati yang ikhlas kepada Allah SWT, tulisan yang mempunyai nilai tarbiyah yang sangat tinggi. Nasih Ulwan mempunyai kredibilitas yang tinggi dalam hal penulisan. Dr. Yusuf al Qardhawi menyatakan bahwa Dr. Abdullah Nasih Ulwan adalah seorang ulama yang sangat dikagumi dari sudut perjuangan dan tulisannya, apa yang ditulis menggambarkan pribadinya yang sangat luhur dan murni. ${ }^{13}$

Setelah pulang dari menghadiri dakwah di Pakistan, Nasih Ulwan telah merasa sakit di bagian dada, itu dia adukan kepada salah seorang doktor perobatan di Universitas Malik Abdul Aziz. Dokter telah menyatakan bahwa dia mengalami penyakit di bagian hati dan paru-paru. Dia dimasukkan ke rumah sakit untuk mendapatkan perawatan dari pakar pengobatan. Dia mendapat perawatan dalam masa yang agak lama di rumah sakit ini. Dia meminta izin untuk keluar dari rumah sakit untuk menunaikan temu janji yang terpaksa dibatalkan semasa berada di rumah sakit. Walaupun dalam keadaan sakit, tugas menyampaikan risalah Islam tetap diteruskan dengan bersusah payah.

Kesakitan pada paru-paru dan hati tidak menghalangi Nasih Ulwan untuk terus aktif menyampaikan kuliah di Universitas dan majlis-majlis dakwah dan seminar. Dia melupakan rasa sakit yang dialami demi Islam tercinta. Dia kemudian dimasukkan kali kedua ke rumah sakit yang sama setelah rasa sakit yang dialaminya semakin kronik. Semasa dirawat di rumah sakit dia banyak menulis bahan ilmiah sebagai ganti memberi kuliah di luar -di samping minat membaca kitab-kitab tetap diteruskan.

Pakar-pakar pengobatan dan beberapa sahabat karib menasihati Nasih Ulwan supaya berhenti membaca dan menulis karena ia akan menghambat perawatan dan menambahkan kesakitan

\footnotetext{
12 http://dakwah.info/main/index.php/biografi-tokoh/405-dr-abdullah-nasih-ulwan 11-06-2009.05:00

13 http://dakwah.info/main/index.php/biografi-tokoh/405-dr-abdullah-nasih-ulwan 11-06-2009.05:00
}

Jurnal Pendidikan Agama Islam

Volume 01 Nomor 01 Mei 2013

Hal $50-60$ 
yang dialami, tetapi Dr. Abdullah Nasih Ulwan hanya tersenyum dan berterima kasih atas keprihatinan mereka serta menyatakan, selagi tangan, mata dan nadinya masih berdenyut, selagi itulah sumbangan kepada dakwah Islamiyah wajib diteruskan. Selagi tangannya mampu memegang pena, selagi itulah dia akan terus menulis. Sampailah keadaannya tidak dapat bangun, dia meletakkan bantal di atas perut untuk menulis dan membaca. Keadaan ini berterusan sehingga dia bertemu Allah SWT.

Dr. Abdullah Nasih Ulwan meninggal dunia pada hari Sabtu Pukul 9.30 Pagi, 5 Muharram 1408 Hijrah, bertepatan dengan 29 agustus 1987 Masehi di rumah sakit Universitas Malik Abdul Aziz, Jeddah, Saudi, dalam usia 59 tahun. Jenazahnya dibawa ke Masjidil Haram untuk disembahyangkan dan dikebumikan di Makkah. Shalat jenazahnya dihadiri oleh ulama-ulama dari seluruh pelosok dunia. ${ }^{14}$ Kepergiannya diiringi oleh perwakilan umat Islam seluruh dunia. Dunia kehilangan ulama murabbi yang benar-benar ikhlas dalam perjuangan menegakkan Islam. Dia telah menyerahkan jiwa raga untuk Islam dengan pengorbanan dan jihad yang sangat besar. Walaupun dia sudah pergi menemui Allah SWT. tetapi dakwahnya tetap berterusan melalui buku dan kitab yang dihasilkan. Semoga Allah mencucuri rahmat ke atas ruhnya, mengampuni segala kesalahan yang dilakukan dan memberikan kekuatan kepada generasi yang memikul amanah dakwah Islamiyah setelahnya. Amin!

Meskipun secara ekplisit Nasih Ulwan tidak pernah mengemukakan tentang pendidikan nilai (value education), pemikiranya sarat dengan ide-ide yang berkenaan dengan upaya menanamkan nilai kepribadian dan etika atau moral dalam anak. Ini sesuai dengan maksud "pendidikan nilai", yakni penanaman dan pengembangan nilai-nilai dalam diri seseorang. Sementara nilai itu sendiri adalah ide atau konsep yang menyebabkan seseorang memandang sesuatu itu penting dalam hidupnya. Nilai bukan benda

14 http://dakwah.info/main/index.php/biografi-tokoh/405-dr-abdullah-nasih-ulwan $\underline{11-06-2009.05: 00}$ 
atau unsur dari benda yang merupakan sifat, kualitas, sui-generis yang dimiliki oleh objek tertentu yang dikatakan baik. ${ }^{15}$

\section{Pendidikan Moral Menurut Nasih Ulwan}

Menurut Nasih Ulwan, pendidikan moral adalah serangkaian prinsip dasar moral dan keutamaan sikap serta watak (tabiat) yang harus dimiliki dan dijadikan kebiasaan oleh anak sejak masa pemula hingga ia menjadi seorang mukallaf, yakni siap mengarungi lautan kehidupan. ${ }^{16}$ Termasuk persoalan yang tidak diragukan adalah bahwa moral, sikap, dan tabiat merupakan salah satu buah iman yang kuat dan pertumbuhan sikap keberagamaan seseorang yang benar.

Jika sejak masa kanak-kanak, seorang anak tumbuh dan berkembang dengan berpijak pada landasan iman kepada Allah SWT. dan terdidik untuk selalu takut, ingat, pasrah, meminta pertolongan dan berserah diri kepada-Nya, ia akan memiliki kemampuan dan bekal pengetahuan di dalam menerima setiap keutamaan dan kemuliaan, disamping terbiasa dengan sikap akhlak mulia. Menurut Ulwan, benteng pertahanan religius yang berakar pada hati sanubarinya, kebiasaan mengingat Allah SWT yang telah dihayati dalam dirinya dan instropeksi diri yang telah menguasai seluruh pikiran dan perasaan, telah memisahkan anak dari sifat-sifat jelek, kebiasaankebiasaan dosa, dan tradisi-tradisi jahiliyah yang rusak. Jadi dasar dari pendidikan moral bagi Ulwan adalah nilai-nilai iman dan takwa kepada Allah SWT.

Hal ini telah dibuktikan dengan keberhasilan yang dilakukan oleh kebanyakan orang tua yang beragama terhadap anak-anaknya, dan para pendidik terhadap murid-muridnya. Percobaan secara praktis ini telah dikenal di dalam perjalanan hidup kaum salaf, seperti yang telah diuraikan dalam sikap Muhammad bin Siwar terhadap putra saudara wanitanya, At-Tustari, ketika ia mendidik dengan landasan iman dan perbaikan pribadi serta tabiatnya. Telah diketahui bahwa diri At-Tustari menjadi baik karena pamannya telah mendidiknya agar selalu ingat, takut dan berlindung kepada Allah SWT, yaitu dengan

\footnotetext{
${ }^{15}$ Mustofa Rohman, "Abdullah Nasih Ulwan: Pendidikan Nilai", 47.

${ }^{16}$ Nasih Ulwan, Pendidikan Anak dalam Islam, 193. 
jalan memerintahkan untuk selalu mengulang kata-kata "Allah bersamaku, Allah melihatku, Allah menyaksikan aku." ${ }^{17}$

Jika pendidikan anak jauh dari pada akidah Islam, lepas dari ajaran religius dan tidak berhubungan dengan Allah SWT, maka tidak diragukan lagi, bahwa anak akan tumbuh dewasa di atas dasar kefasikan, penyimpangan, kesesatan, dan kekafiran. Ia akan meugikuti nafsu dan bisikan-bisikan setan, sesuai dengan tabiat, fisik, keinginan, dan tuntutannya yang rendah. Kalau watak dan sikap anak itu bertipe pasif dan pasrah, maka ia akan hidup sebagai orang yang bodoh. Hidupnya seperti mati, bahkan keberadaannya seperti tidak adanya. Tiada seorang pun yang merasa perlu akan hidupnya, dan kematiannya tidak akan mempunyai arti apapun.

Konsep pendidikan moral yang dikemukakan oleh Ulwan di atas sejalan dengan pandangan Hamka tentang moral. Menurut Hamka -mengacu pada pandangan sosiologi moderen, kebebasan seseorang diikat oleh undang-undang (syari'at), syari'at bersumber dari akhlak atau moral, dan moral atau akhlak bersumber dari kepercayaan kepada Allah SWT." 18 Moral sebagai ajaran Islam, menempati urutan kedua setelah ajaran inti, yaitu ajaran Tauhid. Ini artinya moral dalam Islam seharusnya selalu dijiwai oleh ajaran Tauhid. Sementara syari'ah sebagai ajaran Islam menempati urutan ketiga dari ajaran inti, Tauhid, setelah akhlak (moral). Berarti syari'ah dalam Islam harus selalu dijiwai oleh Tauhid dan moral. Tidaklah boleh syari'at dan pelaksanaannya keluar dari kerangka dan ajaran Tauhid dan moral.

Ajaran moral Nasih Ulwan berupaya mengarahkan manusia agar tidak memiliki sifat kebinatangan, agar manusia tidak kalah oleh sifat-sifat kebinatangan yang ada dalam potensi dirinya. Jika sifat-sifat kebinatangan dapat mengalahkan diri manusia, dengan sendirinya ia akan mengejar segala kesenangan dan kenikmatan dengan segala cara, dengan jalan haram sekalipun. Ia tidak akan merasa malu melakukannya, meski hati dan akalnya akan menghalanginya.

Dengan demikian, pendidikan moral yang berpijak pada iman dan takwa kepada Allah SWT. merupakan faktor yang dapat

${ }^{17}$ Nasih Ulwan, Pendidikan Anak dalam Islam, 194.

${ }^{18}$ Hamka, Pandangan Hidup Muslim, (Jakarta: Bulan Bintang, 1992), hal. 68. 
meluruskan tabiat yang meyimpang dan memperbaiki jiwa kemanusiaan. $^{19}$ Tanpa pendidikan iman, maka perbaikan, ketentraman, dan moral tidak akan tercipta. Para ahli pendidikan dan sosiologi Barat sangat menaruh perhatian akan adanya pertalian yang erat, antara iman dengan moral dan akidah dengan perbuatan. Mereka mengeluarkan beberapa petunjuk, pendapat dan pandangan yang menyatakan, bahwa ketenteraman, perbaikan, dan moral tidak akan tercipta tanpa adanya agama dan iman kepada Allah SWT.

Para orang tua dan pendidik bertanggung jawab untuk membersihkan lidah anak-anak dari kata-kata kotor, dan segala perkataan yang menimbulkan melorotnya nilai moral dan pendidikan. ${ }^{20}$ Mereka bertanggung jawab untuk mengangkat anakanak dari hal-hal yang hina, kebiasaan yang tercela, moral yang buruk dan segala hal yang dapat menjatuhkan kepribadian, kemuliaan, dan kehormatannya. Mereka juga bertanggung jawab untuk membiasakan anak-anak dengan perikemanusiaan yang mulia, seperti berbuat baik kepada anak-anak yatim, kaum fakir, dan mengasihani para janda dan kaum miskin. Amat banyak contoh lain yang merupakan tanggung jawab besar yang berhubungan dengan pendidikan dan moral.

\section{Relevansi Pemikiran Pendidikan Moral Nasih Ulwan dalam Menjawab Problematika Manusia Modern}

Dalam situasi kemanusiaan di zaman modern, harus diakui bahwa terdapat bermacam-macam persoalan yang benar-benar membutuhkan pemecahan segera. Kadang-kadang dirasakan, bahwa situasi yang penuh dengan problematika di dunia modern ini justru disebabkan oleh perkembangan pemikiran manusia sendiri. Di balik kemajuan ilmu dan teknologi, dunia modern sesungguhnya menyimpan suatu potensi yang dapat menghancurkan martabat kemanusiaan. $^{21}$

\footnotetext{
${ }^{19}$ Nasih Ulwan, Menuju Ketakwaan, dalam www.dakwah.info, diakses 09/06/2009, pukul: 04.15

${ }^{20}$ Mustofa Rohman, "Abdullah Nasih Ulwan: Pendidikan Nilai", 48.

${ }^{21}$ Kuntowijoyo, Paradigma Islam: Interpretasi untuk Aksi (Bandung: Mizan, 1991), 159.
} 
Persoalan yang muncul di era modern dapat diidentifikasi sebagai persoalan fisik dan psikis. Persoalan yang bersifat fisik mengarah pada pengkondisian manusia sebagai objek dari segala produk iptek yang dihasilkan di era modern. Sementara itu persoalan yang bersifat psikis mengarah pada pendangkalan nilai-nilai moralspiritual akibat dari dominasi produk keilmuan dan teknologi modern yang bersifat skuler. Fenomena terjadinya Disintegrasi Ilmu, Kepribadian yang Terpecah (split personality), Penyalahgunaan Iptek, Pendangkalan Iman, Pola Hubungan Materialistik, Menghalalkan Segala Cara, Stress dan Frustasi, Kehilangan Harga Diri dan Masa Depan, adalah merupakan bagian dari problem manusia di era modern.

Untuk menyelamatkan manusia dari problematika era modern, perlu intensitas pendidikan moral yang ditanamkan sejak dini kepada anak-anak. Menurut Jalaluddin Rahmat, sekarang ini di seluruh dunia timbul kesadaran betapa pentingnya memperhatikan etika atau moral dalam pengembangan sains. Di beberapa Negara maju telah didirikan lembaga-lembaga "pengawal moral" untuk sains. Lembaga yang paling terkenal ialah The Institut of Society Etics and Life Science di Hasting New York. Kini telah disadari, seperti kata Sir Mac Farlance Burnet, seorang Biolog Australia, bahwa: "Sulit bagi seorang ilmuwan eksperimental mengetahui apa yang tidak boleh diketahui. Ternyata, sains tidak bisa dibiarkan lepas dari etika, kalau manusia tidak ingin senjata makan tuan". ${ }^{22}$

Saat ini dunia sepakat bahwa sains harus dilandasi etikamoral, tetapi karena etika pun akarnya adalah pemikiran filsafat, yaitu pemikiran yang mengandung keunggulan dan kelemahan, maka masalah etika pun masih mengandung masalah. Untuk itu yang diperlukan adalah akhlak yang bersumber pada al-Quran dan alHadist. Terkait dengan ini, amat relevan apabila konsep dan prinsip pendidikan moral yang dikemukakan oleh Abdullah Nasih Ulwan ditanamkan kepada peserta didik sejak dini atau sejak masa kanakkanak. Hal ini akan dapat menghindarkan diri anak jika dewasa nanti dari terkena sikap disintegrasi ilmu, karena ilmu pengetahuan yang

\footnotetext{
${ }^{22}$ Jalaluddin Rahmat, Islam Alternatif (Bandung: Mizan, 1991), 158.
} 
dimiliki didasari dengan etika atau moral. Ajaran moral semacam ini juga akan menjaga manusia dari perbuatan menyalahgunakan ilmu dan teknologi.

Pendidikan moral -menurut Nasih Ulwan- adalah serangkaian prinsip dasar moral dan keutamaan sikap serta watak (tabiat) yang harus dimiliki dan dijadikan kebiasaan oleh anak sejak masa pemula hingga ia menjadi seorang mukallaf, yakni siap mengarungi lautan kehidupan. ${ }^{23}$ Dengan demikian metodenya dapat berupa pembiasaan, tauladan, pembacaan kisah-kisah teladan dari anak-anak shaleh atau shalehah, dan internalisasi atau penanaman moral secara baik.

Nasih Ulwan mendasarkan pemikiran moralnya berdasarkan atas petunjuk al-Quran dan al-Hadits serta perilaku tauladan dari salafush shalihin. Di samping itu, Ulwan mendasarkan pendidikan moralnya pada iman kepada Allah SWT. Jika sejak masa kanakkanak, seorang anak tumbuh dan berkembang dengan berpijak pada landasan iman kepada Allah SWT. dan terdidik untuk selalu takut, ingat, pasrah, meminta pertolongan dan berserah diri kepada-Nya, ia akan memiliki kemampuan dan bekal pengetahuan di dalam menerima setiap keutamaan dan kemuliaan, disamping terbiasa dengan sikap akhlak mulia. Oleh karena Allah itu Satu, maka orang yang berakhlak dengan landasan iman kepada ketauhidan Allah SWT, ia akan terhindar dari problem split personality (kepribadian ganda). Ajaran moral Ulwan juga akan dapat menghindarkan diri seseorang dari kedangkalan iman, karena pendidikan moral Ulwan berlandaskan iman kepada Allah SWT.

Pendidikan moral juga harus dicontohkan dengan kebiasaan mengingat Allah SWT. Menurut Ulwan, benteng pertahanan religius yang berakar pada hati sanubari, kebiasaan mengingat Allah SWT yang telah dihayati dalam dirinya dan instropeksi diri yang telah menguasai seluruh pikiran dan perasaan, telah memisahkan anak dari sifat-sifat jelek, kebiasaan-kebiasaan dosa, dan tradisi-tradisi jahiliyah yang rusak. ${ }^{24}$ Setiap kebaikan akan diterima menjadi salah satu kebiasaan dan kesenangan, dan kemuliaan akan menjadi akhlak dan

\footnotetext{
${ }^{23}$ Nasih Ulwan, Pendidikan Anak dalam Islam, 193.

${ }^{24}$ Nasih Ulwan, Pendidikan Anak dalam Islam, 193. 
sifat yang paling utama. Jadi dasar dari pendidikan moral bagi Ulwan adalah nilai-nilai iman dan ketakwaan kepada Allah SWT. Dengan demikian ajaran moral Ulwan akan dapat menghindarkan diri seseorang dari sikap stress dan frustasi serta akan menjauhkan manusia dari pola hidup hedonistik dan materialistis.

Ajaran moral Nasih Ulwan berupaya mengarahkan manusia agar tidak memiliki sifat kebinatangan, agar manusia tidak kalah oleh sifat-sifat kebinatangan yang ada dalam potensi dirinya. Jika sifat-sifat kebinatangan dapat mengalahkan diri manusia, dengan sendirinya ia akan mengejar segala kesenangan dan kenikmatan dengan segala cara, dengan jalan haram sekalipun. Ia tidak merasa malu melakukannya, meski hati dan akalnya akan menghalanginya. Sifat kebinatangan cenderung mengarahkan manusia pada sikap pemarah jika dalam kondisi di bawah, dan cenderung menjadikan orang congkak dan sewenang-wenang jika dalam kondisi di atas.

Jika tabiat anak itu bertipe aktif dan progresif, ia akan sombong dan takabur di hadapan sesama manusia, menonjolkan kekuasaan dan kesewenang-wenangannya terhadap orang kecil, dan akan bangga dengan ucapan dan perbuatannya. Tidak heran jika di dalam upaya mencapai semua itu akan membuat istana di atas tengkorak-tengkorak manusia dan aliran darah orang-orang yang tidak berdosa. Melihat uraian ini, maka ajaran moral Nasih Ulwan relevan untuk mencegah manusia dari bersikap menghalalkan segala cara demi mencapai tujuan.

Menurut Ulwan, ${ }^{25}$ Islam sangat memperhatikan pendidikan anak-anak dari aspek moral, dan mengeluarkan petunjuk yang sangat berharga dalam membentuk anak dan mengajarkan akhlak yang tinggi. Para pendidik, terutama ayah dan ibu, mempunyai tanggung jawab sangat besar dalam mendidik anak-anak dengan kebaikan dan dasar-dasar moral. Dalam bidang moral ini, tanggung jawab mereka meliputi masalah perbaikan jiwa, meluruskan penyimpangan, mengangkat mereka dari seluruh kehinaan dan menganjurkan pergaulan yang baik dengan orang lain. Mereka bertanggung jawab untuk mendidik anak-anak sejak kecil agar berlaku benar, dapat

${ }^{25}$ Nasih Ulwan, Pendidikan Anak dalam Islam, 194. 
dipercaya, istiqamah, mementingkan orang lain, menolong orang yang membutuhkan bantuan, menghargai orang tua, menghormati tamu, berbuat baik kepada tetangga, dan mencintai orang lain. Hal ini akan berimplikasi pada pencapaian harga diri yang tinggi dan masa depan yang gemilang. Oleh karenanya ajaran moral Nasih Ulwan akan dapat menjawab problem kehilangan harga diri dan masa depan yang banyak dialami oleh manusia modern.

Untuk efektifitas pendidikan moral, Nasih Ulwan menganjurkan kepada para pendidik agar menjauhi sikap-sikap yang tercela dalam Islam. Sikap-sikap tersebut, antara lain: (1) Suka berbohong, (2) Suka mencuri, (3) Suka mencela dan mencemooh, (4) Kenakalan dan penyimpangan. ${ }^{26}$ Harus diakui bahwa salah satu problem mendasar di negeri ini adalah krisis moral dan kepercayaan. Krisis tersebut berawal dari ketidakjujuran dari aparatur Negara dalam menjalankan amanahnya sebagai pemegang kebijakan. Perilaku korupsi dan sejenisnya adalah cermin dari sikap suka bohong, suka mencuri, kenakalan dan penyimpangan, dan hal itu berimplikasi pada sikap suka mencela dan mencemooh. Oleh karena itu ajaran moral Nasih Ulwan amat relevan jika diterapkan di negeri ini demi menjawab problem krisis moral dan kepercayaan yang masih marak terjadi.

\section{E. Analisis Hasil}

Ajaran moral Nasih Ulwan termasuk dalam kategori moral tasawuf, karena mengarahkan manusia pada sikap selalu ingat dan tunduk kepada Allah SWT serta tidak terlena dengan gemerlap kemewahan duniawi. Moral atau ajaran akhlak tasawuf berkenaan dengan ibadah, dzikir, taubat dan berdoa menjadi penting bagi manusia era sekarang, karena membekali manusia untuk tetap mempunyai harapan, yaitu bahagia hidup di akhirat nanti setelah kebahagiaan dunia.

Bagi orang-orang yang sudah lanjut usia, yang dahulu banyak menyimpang hidupnya, akan terus dibayangi perasaan berdosa jika tidak segera bertaubat. Akhlak tasawuf memberikan kesempatan bagi penyelamatan manusia yang demikian. Itu penting dilakukan agar ia tidak

\footnotetext{
${ }^{26}$ Nasih Ulwan, Pendidikan Anak dalam Islam, 200-210. 
terperangkap ke dalam praktik kehidupan spiritual yang menyesatkan, sebagaimana yang akhir-akhir ni banyak berkembang di masyarakat.

Begitu juga munculnya sejumlah anak muda yang terjerumus ke dalam perbuatan tercela, seperti menggunakan obat-obat terlarang, praktik hidup bebas tanpa mempedulikan ajaran agama, dan pikiran mereka telah dipenuhi konsep-konsep yang salah, maka tasawuf dengan sistem yang diakui paling kuat untuk menghubungkan manusia dengan Tuhan, merupakan salah satu alternatif penyembuhan. Proses rehabilitasi korban narkotika dan pergaulan bebas ternyata juga dapat dilakukan melalui jalur tasawuf dan pengembangan akhlaknya. Itulah ajaran moral Nasih Ulwan yang dapat memberikan sumbangan posiitif dan dapat digali serta dikembangkan dari ajaran akhlak tasawuf.

Untuk itu dalam mengatasi problematika kehidupan masyarakat modern saat ini, ajaran moral Nasih Ulwan harus dijadikan salah satu alternatif terpenting. Ajaran moral Nasih Ulwan perlu disuntikkan kedalam seluruh konsep kehidupan. Ilmu pengetahuan, teknologi, ekonomi, sosial, politik, kebdayaan dan lain sebagainya perlu dilandasi dengan ajaran akhlak tasawuf, salah satunya adalah ajaran moral atau akhlak yang dikemukakan oleh Nasih Ulwan.

\section{F. Kesimpulan}

Dalam perspektif Nasih Ulwan, pendidikan moral merupakan serangkaian prinsip dasar moral dan keutamaan sikap serta watak (tabiat) yang harus dimiliki dan dijadikan kebiasaan oleh anak sejak masa pemula hingga ia menjadi seorang mukallaf, yakni siap mengarungi lautan kehidupan. Moral, sikap, dan tabiat merupakan salah satu buah iman yang kuat dan pertumbuhan sikap keberagamaan seseorang yang benar.

Persoalan yang muncul di era modern dapat diidentifikasi sebagai persoalan fisik dan psikis. Persoalan yang bersifat fisik mengarah pada pengkondisian manusia sebagai objek dari segala produk iptek yang dihasilkan di era modern. Sementara itu persoalan yang bersifat psikis mengarah pada pendangkalan nilai-nilai moral-spiritual akibat dari dominasi produk keilmuan dan teknologi modern yang bersifat skuler. Salah satu problem mendasar di negeri ini adalah krisis moral dan kepercayaan. Krisis tersebut berawal dari ketidakjujuran dari aparatur 
Negara dalam menjalankan amanahnya sebagai pemegang kebijakan. Perilaku korupsi dan sejenisnya adalah cermin dari sikap suka bohong, suka mencuri, kenakalan dan penyimpangan. Oleh karena itu ajaran moral Nasih Ulwan amat relevan jika diterapkan di negeri ini demi menjawab problem krisis moral dan kepercayaan yang masih marak terjadi.

\section{DAFTAR PUSTAKA}

Abdullah Nasih Ulwan, 2007, Pendidikan Anak dalam Islam, Jilid I, Terjemahan Jamaludin Miri, Cet. III (Jakarta: Pustaka Aman).

Abdullah Nasih Ulwan, Menuju Ketakwaan, dalam www.dakwah.info, diakses 09/06/2009, pukul: 04.15

Hamka, 1992, Pandangan Hidup Muslim, (Jakarta: Bulan Bintang).

Hanik Yuni Alfiyah, 2008, Ta'lim dan Liberasi (Surabaya: LPPM Press, 2008).

http://elmuttaqie.wordpress.com/2008/05/11/metode-pendidikan-anakmenurut-nashih-ulwan 09/06/09 02.30.35

http://dakwah.info/main/index.php/biografi-tokoh/405-dr-abdullah-nasihulwan 11-06-2009. 05:00

Jalaluddin Rahmat, 1991, Islam Alternatif, (Bandung: Mizan).

Kuntowijoyo, 1991, Paradigma Islam: Interpretasi untuk Aksi, (Bandung: Mizan).

Mustofa Rohman, 2003, "Abdullah Nasih Ulwan: Pendidikan Nilai", dalam A. Khudori Soleh, Pemikiran Islam Kontemporer (Yogyakarta: Jendela).

Said Agil H. M, 2005, Aktualisasi Nilai-nilai Qur'ani dalam Ssistem Pendidikan Islam (Ciputat: PT. Ciputat Press).

www.dakwah.info, diakses 09/06/2009, pukul: 04.15 